\title{
Asbestosis: a study of dose-response relationships in an asbestos textile factory
}

\author{
G. BERRY 1 , J. C. GILSON 1 , S. HOLMES ${ }^{2}$, H. C. LEWINSOHN 2,4 , AND \\ S. A. ROACH \\ From the ${ }^{1}$ MRC Pneumoconiosis Unit, Llandough Hospital, Penarth, South Glamorgan, CF6 $1 X W$, \\ ${ }^{2} T B A$ Industrial Products Limited, Rochdale, Lancashire, OL12 $7 E Q$, and ${ }^{3}$ Imperial Chemical Industries \\ Limited, Wilmslow, Cheshire, SK9 1QB
}

ABSTRACT A group of 379 men who had worked at an asbestos textile factory for at least 10 years has been followed up. The prevalence of crepitations, 'possible asbestosis', certified asbestosis, small opacities in the chest radiograph and values of lung function have been related to dust levels. The type of asbestos processed was predominantly chrysotile although a substantial amount of crocidolite had also been used in the past. There was a higher prevalence of crepitations than had been observed previously at the same factory. The presence of crepitations is not a specific effect of asbestos exposure and 'possible asbestosis', a combined judgement of two physicians on whether a man had developed signs which might be attributable to early asbestosis, was preferred. Fifty per cent of men with a diagnosis of possible asbestosis were certified as suffering from asbestosis by the Pneumoconiosis Medical Panel within $3.5 \mathrm{yr}$. The most reliable data relate to men first employed after $1950 ; 6 \cdot 6 \%$ of men in this group had possible asbestosis after an average length of follow-up of $16 \mathrm{yr}$ and an average exposure to $5 \mathrm{fibre} / \mathrm{cm}^{3}$ where the dust levels were determined by static area samplers. The forced expiratory volume and forced vital capacity declined significantly with exposure, after allowing for age and height, but there was no decline in the total lung capacity. The transfer factor also declined with exposure, but not to a statistically significant extent. The non-smokers and light smokers as a group had less crepitations, asbestosis and small opacities on the chest radiograph than heavier smokers with similar exposure. Combining dust concentrations to form the cumulative dose may not be completely satisfactory, and a family of measures was investigated which allows for elimination of dust from the lungs and includes the cumulative dose as a special case. Because the rate of elimination of dust from the lungs is unknown, and cannot be estimated from the data, this approach leads to a wide range of possible interpretations of the data; for example the concentration such that possible asbestosis occurs in no more than $1 \%$ of men after 40 years' exposure could be as high as $1.1 \mathrm{fibres} / \mathrm{cm}^{3}$ or may have to be as low as $0.3 \mathrm{fibres} / \mathrm{cm}^{3}$. This range is wide because the data relate to higher dust levels, and a shorter period of follow-up. Until data are available on groups exposed to lower levels it will not be possible to assess the effects of the current standard with any certainty. However, the results of this study show that it is important to continue to reduce dust levels to values as low as possible.

In 1968 the British Occupational Hygiene Society (BOHS) published hygiene standards for chrysotile asbestos dust (British Occupational Hygiene Society, 1968). One of the features was that risk was related to accumulated exposure, that is the sum of con-

${ }^{4}$ Present address: Raybestos Manhattan Corporate HQ, 100 Oakview Drive, Trumbull, Connecticut 06611, USA

Received for publication 13 March 1978

Accepted for publication 6 July 1978 centration $\times$ period of exposure to that concentration over the whole period of exposure. With an accumulated exposure of $100 \mathrm{fibre} /$ years $/ \mathrm{cm}^{3}$ it was concluded that it was probable that the risk of contracting asbestosis would be less than $1 \%$, where asbestosis was defined as the earliest demonstrable effect on the lung attributable to asbestos and this effect was the presence of persistent basal rales. The recommendations were made with two main notes of caution. First, it was pointed out that few 
data were available and apart from the early study in the United States (Dreessen et al., 1938) the only relevant data came from an asbestos textile factory in England and concerned 290 men, 16 of whom had basal rales. Second, the conclusions could possibly have been biased because they did not include men who had left the factory, some of whom may have had asbestosis. These two criticisms were repeated by Holmes (1973) and Berry (1973). Another criticism was that dust measurements were not available before 1951. Earlier dust levels were taken as 1.5 times those in 1951 and thus underestimated the cumulative exposure of workers employed during those years.

In this paper we give the results of a subsequent study at the asbestos textile factory considered previously (British Occupational Hygiene Society, 1968). In this work both the medical data and the information about exposures have been improved. First, the time over which observations have been made has been extended by $6.5 \mathrm{yr}$ so that the number of man-years of observation is greater. Second, the system of medical surveillance has been made more systematic and comprehensive by the regular use of lung function tests; in addition, technically improved chest radiography with independent multiple readings using the ILO U/C 1971 classification (International Labour Office, 1972) has been introduced. Third, ex-workers co-operated by returning to the factory for a medical examination and chest radiograph. Finally, personnel and departmental records provided details of all the jobs done by all the men.

This additional study was undertaken for the purpose of reviewing the BOHS Hygiene Standard for chrysotile (British Occupational Hygiene Society, $1968 ;$ 1973). In this paper we are concerned with presenting data and methods of analysis, but not with recommending standards.

The first section of the paper gives details of the methods used in the study and also gives data on dust levels. The second section considers the relationship of the medical findings to dust exposure. The third section explores different dose-response relationships and their effect on hygiene standards for asbestos. This involves discussion of the problems of mathematical modelling (Appendix).

\section{Methods}

THE GROUP STUDIED

The earlier, 1968 study was of men who had worked at the asbestos textile factory for 10 years or more, with all their exposure after 1 January 1933, and who were still employed at the factory on 30 June 1966. In the present study the group is extended to include 89 men who had completed 10 years' service between 30 June 1966 and 31 December 1972. Men who had left the factory after 30 June 1966 were included.

There was one man for whom it was not possible to produce an unambiguous job history. In addition, 12 men had worked for several years (at least 7, average 17) in a subsidiary factory, where they were employed in the preliminary treatment of crude asbestos. Dust conditions at this factory are unknown for the period in question, but were probably markedly different from those in the main factory. After excluding these 13 men a total of 379 men remained.

\section{MEDICAL INFORMATION}

For all the men the following were obtained from the records in the factory's medical department:

(i) the most recent chest radiograph;

(ii) the date of the most recent medical examination; the date on which basal crepitations (rales) that did not clear on coughing were first heard; and the date of the previous medical examination;

(iii) the date on which the factory medical officer first suspected possible asbestosis and the date of the previous medical examination;

(iv) the most recent measurement of forced expiratory volume $\left(\mathrm{FEV}_{1.0}\right)$, forced vital capacity $(\mathrm{FVC})$, functional residual capacity (FRC), total lung capacity (TLC), residual volume (RV), transfer factor (TL) by the single breath technique, and pulmonary arterial pressure of carbon dioxide $\left(\mathrm{PaCO}_{2}\right)$, together with height, weight, and smoking habits. Because tests of pulmonary function were not introduced until 1967, these data were available on only 311 , or $82 \%$ of the men.

All the men who had left after 30 June 1966 were invited to attend for a chest radiograph and medical examination. Sixty-eight out of $113(60 \%)$ accepted this invitation, $13(12 \%)$ refused or failed to attend, and the remaining $32(28 \%)$ did not reply. However, there were only 20 men still living who had not been seen in 1970 or more recently. None of these 20 men had been certified as suffering from asbestosis by the end of 1975 . Ninety-three per cent of the men in the study had been medically examined or had a chest radiograph since 1969 or within three years of death.

The men working in scheduled occupations have periodic medical examinations by a Pneumoconiosis Medical Panel under the Prescribed Diseases Regulations of the National Insurance (Industrial Injuries) Act, 1946. In addition, some men applied to the Panel for certification as having asbestosis. We were allowed access to the records at the Pneumoconiosis Medical Panel for the men in the study and noted whether crepitations had been recorded at 
the periodic examinations and which men had been certified as having asbestosis, together with the date of certification and degree of disability. Information on certification is complete up to 1975 on all men, including those who had left the factory.

The diagnosis of asbestosis is based upon the presence of physical signs of pulmonary fibrosis, radiological appearance and lung function defects. McVittie (1965) indicated that the Pneumoconiosis Medical Boards diagnosed asbestosis in the presence of a history of adequate exposure, on the finding of end-inspiratory basal rales, finger clubbing, radiological abnormality and reduction of lung function such as transfer factor and vital capacity. Adequate exposure plus two of the other relevant criteria listed above is sufficient for diagnosis but the Board must be satisfied that the individual is disabled, before certifying asbestosis.

It has been the practice of the factory medical officer to examine all asbestos workers routinely every two years, and to advise them to change to less dusty jobs if he believes that they are developing symptoms or signs of early asbestosis. He bases his suspicions on the finding of basal rales or crepitations, radiological changes of varying degree, a falling gas transfer factor, and restrictive changes in lung volume or ventilatory capacity. This condition is referred to as 'possible asbestosis' and is a diagnosis based on signs insufficient to attract Disablement Benefit. The company has supported this policy by paying workers with possible asbestosis, who change jobs, a guaranteed basic wage plus an ex gratia payment.

Workers were given chest radiographs every three years from 1951 until 1967 and every year since then. Lung function tests were introduced in May 1967 and are carried out every two years.

The most recent radiographs were read in random order, and without knowledge of the men's identities or job histories, by four readers independently using the ILO/UC 1971 classification (International Labour Office, 1972). The four readings of small opacities were combined by scoring the categories $0 / 0,0 / 1, \ldots, 3 / 4$ as $0,1, \ldots, 10$ and taking the average score. In most instances the profusion of irregular opacities exceeded that of rounded opacities, but whichever type gave the higher reading was that which was averaged; there were only five films in which the profusion of rounded opacities was the greater, and in all of these the average profusion was $0 / 1$ or less.

The factory medical officer had originally diagnosed 60 cases of possible asbestosis. A clinician (JCG) reviewed the medical data for each man without knowing his occupational history, and noted where his opinion on the presence or absence of possible asbestosis differed from that of the factory medical officer. There were 12 men, placed by the latter in the possible asbestosis group, but for whom none or only one reader had recorded a profusion of small opacities of $1 / 0$ or more, and there were 37 men whom only the clinician had placed in this group, for whom at least two readers recorded $1 / 0$ or more. The clinician and factory medical officer examined the complete medical files of these 49 men together and reached agreement on a diagnosis. Seven men were removed from the possible group and five were added to it. The most common reason for considering a case not to be possible asbestosis was that it was thought more likely that the signs were attributable to other disease. This shows that the diagnosis of asbestosis cannot be made without considering all the clinical evidence, and sole reliance cannot be placed on any single feature used for diagnostic purposes.

\section{DUST EXPOSURE}

Details of all the jobs performed by each man were noted by an independent industrial hygienist (SAR) who visited the factory and examined the employment records. In all, 236 job descriptions were used. For each job description a dust level was calculated for each year by taking the average of the levels measured at the static dust sampling locations in the area where the job was carried out. In all, 64 sampling locations had been used over the period 1961-72.

Fibre counts were not available for 1951-60, but thermal precipitator particle counts were available for 1952 and 1960. The fibre counts for 1951-55 were taken as those of 1961 multiplied by the ratio of the 1952 to the 1960 thermal precipitator measurements. This ratio was dependent on job, ranging from 1.4 to 3.4 (British Occupational Hygiene Society, 1968). The counts for 1956-60 were taken to be the same as 1961-65. There were no dust measurements before 1950. For 1933-45 the concentrations were taken to be 1.5 times those in 1951 and for 1946-50 as 1.25 times the 1951 values. These concentrations, particularly for the early years, are probably underestimates of the actual concentrations (British Occupational Hygiene Society, 1968).

Some men were coded as doing more than one job at the same time; the dust level in these cases has been taken as the mean of the concentrations for the different jobs. When a man was away from the factory, or at the factory but working in a job away from the production area, it was assumed that he was not exposed to asbestos.

As an indication of the dust conditions within the factory Table 1 gives the mean dust level and the percentage of men in the study within the ranges 
Table 1 Dust exposure of men employed in certain years

\begin{tabular}{|c|c|c|c|c|}
\hline Year & $\begin{array}{l}\text { Mean dust } \\
\text { level }\left(\mathrm{f} / \mathrm{cm}^{3}\right)\end{array}$ & $\begin{array}{l}\text { Percentag } \\
<2 f / \mathrm{cm}^{3}\end{array}$ & $\begin{array}{c}f \text { men exposed } \\
2 \cdot 1-5 f / \mathrm{cm}^{3}\end{array}$ & $\stackrel{t o}{>5 f / \mathrm{cm}^{3}}$ \\
\hline $1936^{*}$ & $13 \cdot 3$ & 0 & 0 & 100 \\
\hline $1941^{*}$ & $14 \cdot 5$ & 4 & 0 & 96 \\
\hline $1946^{*}$ & $13 \cdot 2$ & 2 & 2 & 96 \\
\hline $1951 \dagger$ & $10 \cdot 8$ & 3 & 8 & 89 \\
\hline $1956 \dagger$ & $5 \cdot 3$ & 2 & 40 & 58 \\
\hline 1961 & $5 \cdot 2$ & 6 & 35 & 59 \\
\hline 1966 & $5 \cdot 4$ & 23 & 22 & 55 \\
\hline 1972 & $2 \cdot 9$ & 32 & 65 & 3 \\
\hline
\end{tabular}

* There were no dust measurements in these years and the dust levels given are considered to be lower limits.

†Fibre counts not made in these years (see text).

less than 2 fibres (f) $/ \mathrm{cm}^{3}, 2-5 \mathrm{f} / \mathrm{cm}^{3}$ and more than $5 \mathrm{f} / \mathrm{cm}^{3}$ for certain years, for those men in the study who were working in production areas on 31 December of the year concerned.

From 1933, most of the asbestos used in the factory, amounting to many thousands of tonnes, has been chrysotile. In addition, about 2500 tonnes of crocidolite have passed through all the textile processes.

PREVALENCE AND INCIDENCE

The results are quoted as either prevalences or incidences. The prevalence is the proportion or percentage of men with a defined condition at one point in time. The incidence is the rate of appearance of conditions in previously unaffected men, and is given as the proportion or percentage per annum.

\section{Results}

NUMBER OF MEN WITH CREPITATIONS, POSSIBLE ASBESTOSIS AND CERTIFIED

ASBESTOSIS

Eighty-two men were recorded as having crepitations when last examined, 58 had possible asbestosis, and 34 were certified as having asbestosis. There was considerable overlap between these three conditions
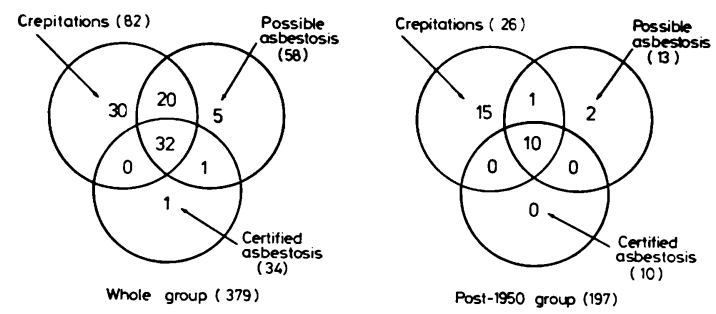

Fig. 1 Number of men with combinations of conditions (crepitations, possible asbestosis and certified asbestosis) for whole group and for those first employed after 1950 . and 89 had one or more of them (Figure 1).

One man was certified on post-mortem findings. In addition, out of 19 deceased non-certified cases, there were three where asbestos exposure was considered contributory to death, and who might have been certified if an application had been made. None of these four men had been suspected of suffering from asbestosis during life. Eight men who had been certified during life have since died. In three of these, asbestosis was not recorded at post-mortem examination; however, histological material for two of these three cases was reviewed later, and there was evidence of slight asbestosis in both.

Table 2 summarises various aspects of exposure at the factory, and ages are given. For those with signs (crepitations, possible or certified asbestosis) and the three men who could have been certified at death, the cumulative exposures, years since first exposure and ages have been calculated up to the first occurrence of the signs. This means that, within exposure categories, the data cannot be interpreted as prevalences; for example, for those first employed after 1950 although $4(11 \%)$ out of 36 with less than $50 \mathrm{f}-\mathrm{yr} / \mathrm{cm}^{3}$ had signs, the other $161 \mathrm{men}$ are known to have reached $50 \mathrm{f}-\mathrm{yr} / \mathrm{cm}^{3}$ without signs. The prevalences can be calculated using life-table methods and at $50 \mathrm{f}-\mathrm{yr} / \mathrm{cm}^{3}$ the prevalence is $2 \%$, not $11 \%$.

Most of the signs were first observed after 30 June 1966 and, for men first employed after 1950 and whose cumulative exposure was less than $100 \mathrm{f}-\mathrm{yr} /$ $\mathrm{cm}^{3}$ in 1966, the incidence rates since then were $1.6,0.7$ and $0.5 \%$ per annum for crepitations, possible asbestosis and certified asbestosis respectively.

COMPARISON OF RECORDS OF CREPITATIONS BY FACTORY MEDICAL OFFICER AND BY PNEUMOCONIOSIS MEDICAL PANEL (PMP)

All except two of the men in the study had been seen at some time by the PMP. The recording of crepitations by the factory medical officer and by the PMP are summarised in Table 3. Although there was agreement on the proportion of men with crepitations, there were 58 men for whom the records of the factory medical officer and the PMP did not agree. Some of these discrepancies were attributable to the time of the examination; for example, seven of the men read as positive by the factory medical officer and negative by the PMP had been seen more recently by the former. Other discrepancies were probably caused by the transient nature of the sign in some men and also, no doubt, by genuine observer differences. More detailed analysis showed that there was a significant excess $(P<0.01)$ of men with low exposures among those 
Table 2 Summary of exposure at factory

\begin{tabular}{|c|c|c|c|c|}
\hline \multirow[t]{2}{*}{ Exposure factors } & \multicolumn{2}{|c|}{ Workers first employed before 1951} & \multicolumn{2}{|c|}{ Workers first employed after 1950} \\
\hline & Total & With signs & $\widehat{\text { Total }}$ & With signs \\
\hline \multicolumn{5}{|c|}{ Year started at factory } \\
\hline $1933-35$ & 11 & 7 & - & - \\
\hline $1936-40$ & 50 & 21 & - & - \\
\hline $1941-45$ & 28 & 11 & - & - \\
\hline $1946-50$ & 93 & 23 & - & - \\
\hline $1951-55$ & - & - & 109 & 22 \\
\hline $1956-60$ & - & - & 75 & 6 \\
\hline $1961-65$ & - & - & 13 & 2 \\
\hline \multicolumn{5}{|c|}{$\begin{array}{l}\text { Maximum annual time-weighted average } \\
\text { concentration }\left(\mathrm{f} / \mathrm{cm}^{3}\right)\end{array}$} \\
\hline$<5$ & 1 & 0 & 11 & 1 \\
\hline $5-9.99$ & 38 & 9 & 82 & 9 \\
\hline $10-19.99$ & 70 & 26 & 92 & 18 \\
\hline $20-50$ & 73 & 27 & 12 & 2 \\
\hline \multicolumn{5}{|c|}{ Cumulative exposure* $\left(\mathrm{f}-\mathrm{yr} / \mathrm{cm}^{3}\right)$} \\
\hline$<50$ & 5 & 1 & 36 & 4 \\
\hline $50-99$ & 25 & 6 & 95 & 12 \\
\hline $100-149$ & 36 & 12 & 52 & 13 \\
\hline $150-199$ & 44 & 17 & 14 & 1 \\
\hline $200-249$ & 39 & 11 & - & - \\
\hline $250-549$ & 33 & 15 & - & - \\
\hline \multicolumn{5}{|c|}{ Time since first employed at factory* $(y r)$} \\
\hline$<10$ & 1 & 0 & 9 & 1 \\
\hline $10-14$ & 0 & $\mathbf{0}$ & 74 & 16 \\
\hline $15-19$ & 17 & 12 & 114 & 13 \\
\hline $20-24$ & 65 & 19 & & \\
\hline $25-29$ & 51 & 16 & & \\
\hline $30-39$ & 48 & 15 & & \\
\hline \multicolumn{5}{|l|}{$\operatorname{Age}^{*}(\mathrm{yr})$} \\
\hline$<40$ & 3 & 0 & 36 & 0 \\
\hline $40-44$ & 5 & 0 & 25 & 3 \\
\hline $45-49$ & 22 & 8 & 31 & 4 \\
\hline $50-54$ & 34 & 13 & 35 & 4 \\
\hline $55-59$ & 52 & 22 & 33 & 11 \\
\hline $60-72$ & 66 & 19 & 37 & 8 \\
\hline Total & 182 & 62 & 197 & 30 \\
\hline
\end{tabular}

*For those with signs, these are calculated up to the first occurrence of the signs.

Table 3 Number of men with crepitations recorded by factory medical officer or by Pneumoconiosis Medical Panel

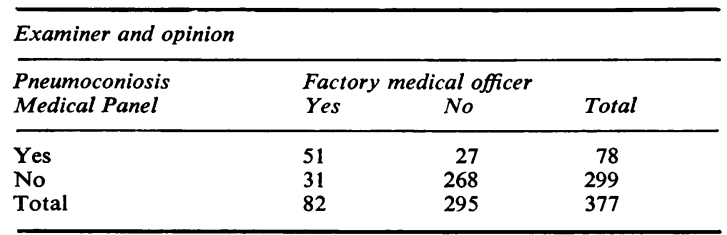

in whom crepitations were heard at the factory but were not heard by the PMP.

RELATIONSHIP BETWEEN POSSIBLE

ASBESTOSIS AND CERTIFICATION

Except for the one man who was certified after death, and had not been seen in the factory medical department within the previous 10 years, all the certified cases were also in the possible category. An analysis, using life-table techniques, has been carried out on the interval between suspicion and certification. The results are given in Figure 2, which shows the cumulative percentage of certified cases plotted against time since suspicion; $25 \%$ became certified within 15 months of suspicion and $50 \%$ within $3.5 \mathrm{yr}$. Of 19 men who were uncertified after five years' follow-up since first suspicion, only one was subsequently certified in, on average, a further two years' follow-up.

\section{RADIOLOGICAL FINDINGS, LUNG FUNCTION AND EXPOSURE}

The profusion of small opacities and bilateral pleural thickening have been related to cumulative dust exposure (Table 4). Again, these data cannot be 


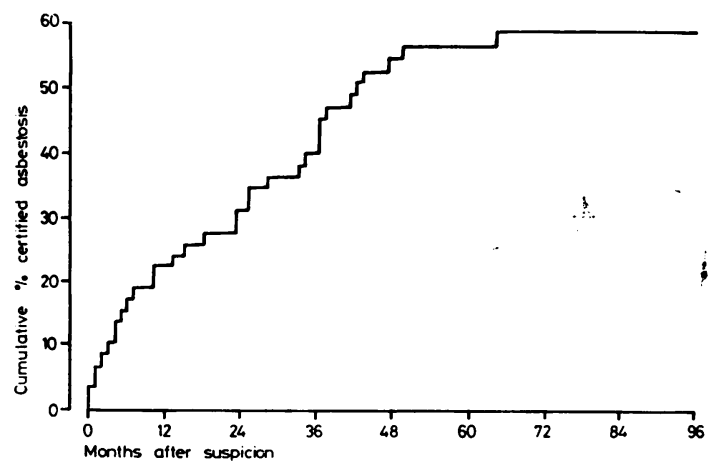

Fig. 2 Time between suspicion and certification of asbestosis.

interpreted as prevalences within the separate exposure categories because some of those subjects with radiological abnormalities were suspected to have asbestosis and were therefore transferred to less dusty conditions.

The lung function measurements have been expressed as percentages of predicted values allowing for age and height (see footnote to Table 5).Theanalysis was restricted to Caucasians first employed after 1950 (141 men) and the mean lung function values within exposure categories are shown in Figure 3. Table 5 shows the regression coefficients on cumulative exposure. FEV 1.0 and FVC were significantly
Table 5 Regression coefficients of lung function indices and exposure in men first employed after 1950

\begin{tabular}{ll}
\hline Index & $\begin{array}{l}\text { Regresssion coefficient } \pm \text { standard error } \\
(\% \text { predicted }\end{array}$ f-yr/cm $\left.^{3}\right)$
\end{tabular}

* The predicted values were calculated from the reference relationships used in the factory; these relationships were calculated on men not exposed to asbestos and allow for age $(a, y r)$ and height $(h, \mathrm{~m})$ :FEV $_{10}=2.72 h-0.039 a+0.48 ; \mathrm{FVC}=6.54 h-0.032 a-5.38$ $\mathrm{TLC}=7.24 h-0.028 a-5.43 ; \mathrm{TL}=32.0 h-0.20 a-17.0$.

related to exposure but there was no evidence of a relationship for TLC; the relationship for TL could have arisen by chance but cannot be considered to be unimportant.

THE INFLUENCE OF SMOKING

Information regarding smoking habits was available for all except three of the men. The associations between the most recent smoking habits and crepitations, possible and certified asbestosis, and small opacities, are shown in Table 6. The cumulative exposure was similar for each smoking category, as also was the time since first exposure to asbestos. For men first exposed after 1950 there are clear indications that non-smokers and light smokers are less likely to have any of the conditions. However

Table 4 Radiological findings and exposure

\begin{tabular}{|c|c|c|c|c|c|c|}
\hline \multirow{2}{*}{$\begin{array}{l}\text { Cumulative exposure } \\
\left(f-y r / \mathrm{cm}^{3}\right)\end{array}$} & \multirow[t]{2}{*}{ Total } & \multicolumn{4}{|c|}{ Profusion of small opacities* } & \multirow{2}{*}{$\begin{array}{l}\text { Bilateral pleural } \\
\text { thickening } \dagger\end{array}$} \\
\hline & & $0 / 1$ & $1 / 0$ & $1 / 1$ & $1 / 2$ or more & \\
\hline \multicolumn{7}{|c|}{ First employment before 1951} \\
\hline$<25$ & 2 & 1 & 0 & $\mathbf{0}$ & 0 & 0 \\
\hline $25-49$ & 2 & 1 & 0 & 0 & $\mathbf{0}$ & 0 \\
\hline $50-74$ & 9 & 2 & 2 & 1 & 0 & 2 \\
\hline $75-99$ & 15 & 3 & 3 & 0 & $3(1 / 2,1 / 2,1 / 2)$ & 4 \\
\hline $100-124$ & 8 & 4 & 0 & 0 & $1(3 / 3)$ & 0 \\
\hline $125-149$ & 29 & 7 & 4 & 4 & $1(1 / 2)$ & 1 \\
\hline $150-174$ & 20 & 7 & 4 & 1 & 0 & 2 \\
\hline 175-199 & 25 & 4 & 4 & 0 & $1(3 / 2)$ & 2 \\
\hline $200-224$ & 22 & 3 & 5 & 2 & $1(2 / 2)$ & 3 \\
\hline $225-249$ & 16 & 4 & 3 & 0 & $2(1 / 2,1 / 2)$ & 1 \\
\hline$\geqslant 250$ & 34 & 6 & 10 & 2 & $5(1 / 2,2 / 1,2 / 1,2 / 2,2 / 2)$ & 4 \\
\hline Total & 182 & 42 & 35 & 10 & 14 & 19 \\
\hline \multicolumn{7}{|c|}{ First employment after 1950} \\
\hline$<25$ & 5 & 1 & $\mathbf{0}$ & 0 & 0 & 1 \\
\hline $25-49$ & 31 & 10 & 2 & 0 & $1(1 / 2)$ & 2 \\
\hline $50-74$ & 59 & 9 & 5 & 3 & $1(1 / 2)$ & $\overline{2}$ \\
\hline $75-99$ & 37 & 14 & 1 & 1 & $1(3 / 3)$ & 3 \\
\hline $100-124$ & 26 & 2 & 5 & 0 & $1(2 / 1)$ & 0 \\
\hline $125-149$ & 22 & 6 & 3 & o & $1(2 / 2)$ & 1 \\
\hline$\geqslant 150$ & 17 & 4 & 2 & 2 & 0 & o \\
\hline Total & 197 & 46 & 18 & 6 & 5 & 9 \\
\hline
\end{tabular}

*Average of 4 readers; if the average was halfway between two adjacent categories the reading was rounded downwards (there were 27 such cases between $0 / 0$ and $0 / 1$ ).

tAt least 2 of the 4 readers recording bilateral pleural thickening. 


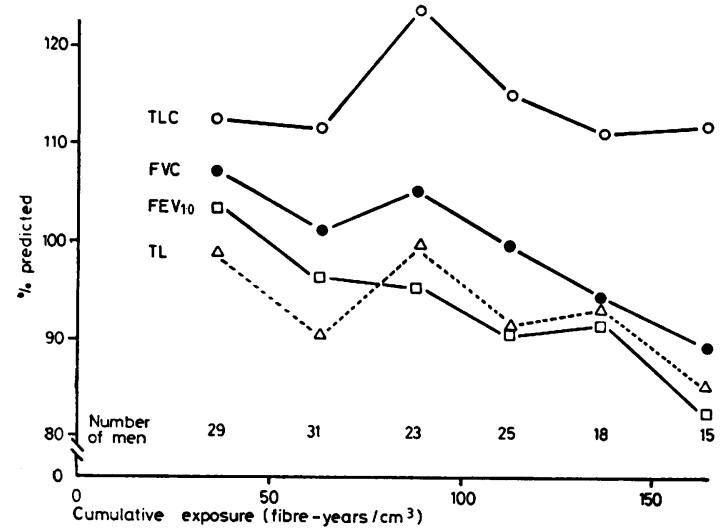

Fig. 3 The relationship between indices of lung function and cumulative exposure to asbestos, for men first employed after 1950. the non-smokers were on average younger than the smokers, aged 55 years compared with 58 years for those first employed before 1951, and 47 years compared with 52 years for those first employed after 1950. The data are shown in age groups in Table 7. After taking account of age, there were significantly fewer signs in non-smokers and light smokers than in heavier and ex-smokers, for men first exposed after 1950: for crepitations, $P<0.01$; for possible and certified asbestosis, $P<0.1$ and for small opacities $P<0.05$.

\section{Dose-response relationships}

The dose-response relationships considered in this section are those between the prevalence or incidence of one of the three signs (crepitations, possible, or certified asbestosis) and a measure of dust exposure. The mathematical forms of dose-response relationships and a discussion of methods for combining the

Table 6 The association between smoking and signs of asbestosis

\begin{tabular}{|c|c|c|c|c|c|c|}
\hline \multirow[t]{2}{*}{ Employment group and smoking habit } & \multirow{2}{*}{$\begin{array}{l}\text { Mean } \\
\text { cumulative } \\
\text { exposure } \\
\left(f-y r / c^{3}\right)\end{array}$} & \multicolumn{5}{|c|}{ Numbers of men } \\
\hline & & $\overline{\text { Total }}$ & Crepitations & $\begin{array}{l}\text { Possible } \\
\text { asbestosis }\end{array}$ & $\begin{array}{l}\text { Certified } \\
\text { asbestosis }\end{array}$ & $\begin{array}{l}\text { Small } \\
\text { radiological } \\
\text { opacities* }\end{array}$ \\
\hline \multicolumn{7}{|l|}{ First employed before 1951} \\
\hline Never smoked & 197 & 22 & 4 & 3 & 2 & 4 \\
\hline 1-4 cigarettes/day & 109 & 7 & 3 & 3 & 1 & 2 \\
\hline 5-14 cigarettes/day & 188 & 62 & 22 & 15 & 7 & 18 \\
\hline $15+$ cigarettes/day & 197 & 62 & 20 & 18 & 9 & 22 \\
\hline Ex-smokers & 192 & 28 & 7 & 6 & 5 & 13 \\
\hline \multicolumn{7}{|l|}{ First employed after 1950} \\
\hline Never smoked & 79 & 42 & 0 & $\mathbf{0}$ & $\mathbf{0}$ & 2 \\
\hline 1-4 cigarettes/day & 91 & 13 & $\mathbf{0}$ & $\mathbf{0}$ & $\mathbf{0}$ & $\mathbf{0}$ \\
\hline 5-14 cigarettes/day & 89 & 48 & 11 & 6 & 5 & 11 \\
\hline $15+$ cigarettes/day & 84 & 68 & 11 & 4 & 3 & 11 \\
\hline Ex-smokers & 81 & 24 & 4 & 3 & 2 & 4 \\
\hline
\end{tabular}

*Profusion $1 / 0$ or more.

Table 7 The association between smoking, age and signs of asbestosis

\begin{tabular}{|c|c|c|c|c|c|c|}
\hline \multirow[t]{2}{*}{ Employment group and smoking habit } & \multirow[t]{2}{*}{ Age group } & \multicolumn{5}{|c|}{ Numbers of men } \\
\hline & & Total & Crepitations & $\begin{array}{l}\text { Possible } \\
\text { asbestosis }\end{array}$ & $\begin{array}{l}\text { Certified } \\
\text { asbestosis }\end{array}$ & $\begin{array}{l}\text { Small } \\
\text { radiological } \\
\text { opacities }\end{array}$ \\
\hline $\begin{array}{l}\text { First employed before } 1951 \\
\text { Never smoked and } 1-4 \text { cigarettes per day } \\
\text { Other smokers and ex-smokers }\end{array}$ & $\left\{\begin{array}{l}-54 \\
55+ \\
-54 \\
55+\end{array}\right.$ & $\begin{array}{r}11 \\
18 \\
37 \\
115\end{array}$ & $\begin{array}{r}0 \\
7 \\
7 \\
42\end{array}$ & $\begin{array}{r}0 \\
6 \\
5 \\
34\end{array}$ & $\begin{array}{r}1 \\
2 \\
2 \\
19\end{array}$ & $\begin{array}{r}0 \\
6 \\
6 \\
47\end{array}$ \\
\hline $\begin{array}{l}\text { First employed after } 1950 \\
\text { Never smoked and } 1-4 \text { cigarettes per day } \\
\text { Other smokers and ex-smokers }\end{array}$ & $\left\{\begin{array}{l}-44 \\
45-54 \\
55+ \\
-44 \\
45-54 \\
55+\end{array}\right.$ & $\begin{array}{l}26 \\
17 \\
12 \\
32 \\
51 \\
57\end{array}$ & $\begin{array}{r}0 \\
0 \\
0 \\
0 \\
8 \\
18\end{array}$ & $\begin{array}{l}0 \\
0 \\
0 \\
0 \\
5 \\
8\end{array}$ & $\begin{array}{l}0 \\
0 \\
0 \\
0 \\
4 \\
6\end{array}$ & $\begin{array}{r}1 \\
0 \\
1 \\
1 \\
10 \\
15\end{array}$ \\
\hline
\end{tabular}

*Profusion $1 / 0$ or more. 
dust levels experienced at different times into measures of exposure are given in the Appendix.

If the factory medical officer suspected that a man had asbestosis, then he would recommend transfer to a less dusty job. Such a modification to a man's exposure based on medical signs is of relevance to the methods used to relate these signs to dust exposure; an unbiased analysis can be made only by using the times at which men with positive signs first reached this stage. The observed dose-response relationship is obtained using life-table methods.

\section{RELATIONSHIP OF SIGNS TO CUMULATIVE} DUST EXPOSURE

The simplest measure of exposure is the integrated dust concentration over the period of exposure. This measure, which is the one used previously (British Occupational Hygiene Society, 1968), gives equal weight to a given concentration without taking into account when the exposure occurred. The data are first presented in terms of this measure of dust exposure, and for all the men in the study.

The dose-response relationship (British Occupational Hygiene Society, 1968) was based on the assumption that the distribution of exposure at which a sign first occurred was log-normal. A similar approach has been followed, except that the logit transformation has been used instead of the probit transformation, and the relationship fitted to the signs (crepitations, possible asbestosis, and certified asbestosis).

In the 1968 analysis, it was estimated that $1 \%$ of those exposed would have crepitations after a dose of $112 \mathrm{f}-\mathrm{yr} / \mathrm{cm}^{3}$ with $90 \%$ confidence limits of 51 and $153 \mathrm{f}-\mathrm{yr} / \mathrm{cm}^{3}$. In the present analysis the response at a given dose is higher, and a prevalence of $1 \%$ is estimated at $43 \mathrm{f}-\mathrm{yr} / \mathrm{cm}^{3}(90 \%$ confidence limits, 34 and 52). For possible and certified asbestosis the $1 \%$ prevalences are estimated at 55 and 72 $\mathrm{f}-\mathrm{yr} / \mathrm{cm}^{3}$ respectively. These figures are given as illustrations only, and not as suggested standards; other points have to be taken into account in setting standards.

There are three reasons for the differences in the dose-response relationships for crepitations between 1966 and 1972. First, the dust exposures are now known more accurately and, in particular, it is known that some men spent part of their time in less dusty jobs than the job category defined in 1966 . The effect of this extra information is that the average cumulative dose up to 1966 is now estimated as about two-thirds of what it previously was thought to be. Thus the figure of $112 \mathrm{f}-\mathrm{yr} / \mathrm{cm}^{3}$ originally calculated represents about $75 \mathrm{f}-\mathrm{yr} / \mathrm{cm}^{3}$. Second, crepitations were recorded more frequently than previously $(82 / 379=22 \%$ compared with $16 / 290=$
$6 \%$ in 1966). This is attributable both to the longer follow-up and to a difference between observers; the factory medical officer changed in 1967. Third, the 1966 data were taken entirely from men still working at the factory whereas in the present study this selective effect, although still present, has been reduced by including men who left the factory between studies. As an indication of the difference this makes, if the analysis had been carried out only on those still employed at the end of 1972, then the prevalence of crepitations would have been $17 \%$ $(42 / 241)$ instead of $22 \%$. This selective leaving appeared not to be caused by crepitations as such, but may have followed certification which was correlated with crepitations; 29 out of 34 workers with certified asbestosis were not employed at the factory at the end of 1972 .

\section{DATE OF FIRST EMPLOYMENT}

Dust conditions in the factory were measured only from 1951 onwards. The above analysis depends on assumptions of the dust conditions in the period 1933-50, but an analysis restricted to men first employed from 1951 onwards does not. In addition, such an analysis largely eliminates the bias caused by the exclusion of those who left the factory before 1966. For this reason, the analyses have been repeated for the group of men starting at the factory after 1950 (Figure 1). Figure 4 shows the observed and fitted relationships between the three signs and cumulative dose for men first employed after 1950 . The exposures giving $1 \%$ prevalences were 37,46 , and $63 \mathrm{f}-\mathrm{yr} / \mathrm{cm}^{3}$ for crepitations, possible asbestosis and certified asbestosis respectively; again, these figures are given as illustrations only.

LIMITATIONS OF CUMULATIVE EXPOSURE Relating the prevalence of disease to the dust concentrations weighted by duration of exposure to them is unsatisfactory because this ignores the probability of developing disease after exposure has ended. This disadvantage may be overcome by using a measure of exposure which weights the dust concentration at any moment by the time that has elapsed since exposure (Jahr, 1974). Such a measure attaches more importance to exposure a long time ago than to more recent exposure, and continues to increase after exposure has ended. When applied to men first exposed after 1950 it gives quite different interpretations from those of Figure 4; for example, $1 \%$ crepitations occurred at a dose of $163 \mathrm{f}-\mathrm{yr}^{2} / \mathrm{cm}^{3}$ which represents the dose accumulated by the end of 50 years' uniform exposure to a concentration of $0.13 \mathrm{f} / \mathrm{cm}^{3}$. (Using the unweighted cumulative exposure, the same risk occurred at the dose from 50 years' exposure to $0.74 \mathrm{f} / \mathrm{cm}^{3}$ ). For possible 


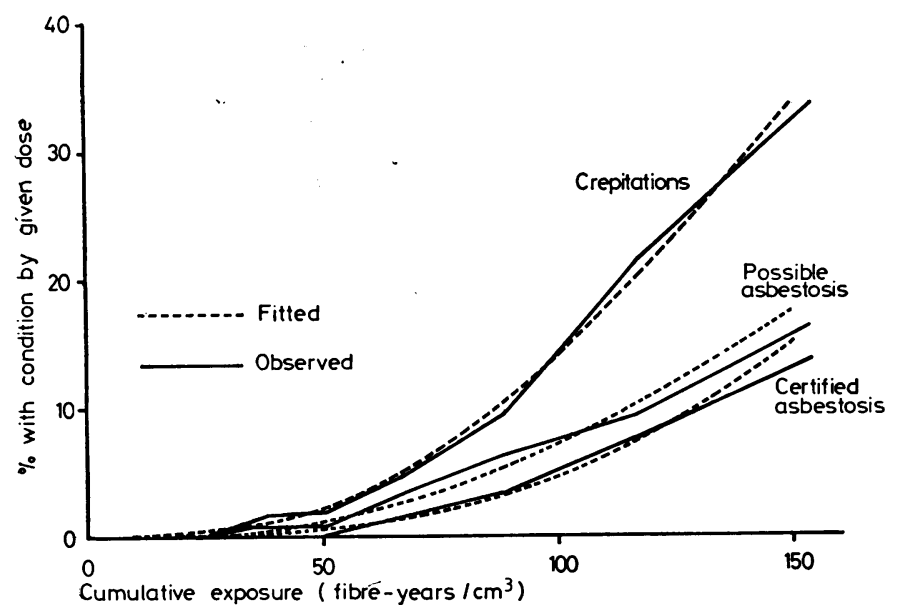

Fig. 4 The relationships between the percentage developing the conditions, crepitations, possible asbestosis and certified asbestosis, and cumulative exposure to asbestos, for men first employed after 1950. The observed relationships were obtained by life table methods. and certified asbestosis the $1 \%$ prevalences correspond to 50 years' exposure to 0.19 and $0.37 \mathrm{f} / \mathrm{cm}^{3}$ respectively.

Thus, the choice of a suitable measure of exposure is highly critical, and it is not known what measure is most appropriate. If, over a long period, dust is eliminated from the lungs at a rate proportional to the amount present, and disease is caused by cumulative dose weighted by residence time of each contribution, then a family of exposure measures is produced. This family is indexed by the rate of exponential elimination, or half-life time, and, as extreme cases, contains the cumulative dose (halftime zero) and the cumulative dose weighted by time since exposure (half-time infinity). Further details are given in the Appendix.

This family of curves has been fitted to crepitations and possible asbestosis for a number of half-life times for men first employed after 1950. It was impossible to estimate precisely the half-life time giving the best fit to the data, and any value in excess of three years was considered to be adequate. Failure to estimate the half-life time reliably is not surprising, because the critical data would be observations on men who had left the factory many years previously.

Another way in which the exposure measure may be inappropriate is that a given dose is assumed to be effective immediately. The measure can be amended to accommodate a lag period for the development of an observed effect by assuming that, however severe the exposure, disease is not observed until some minimum time has elapsed since the start of exposure. There are insufficient data to estimate this lag period and the model was fitted incorporating a lag of five years.

Cumulative dose is correlated with years since first exposure; using this time as a measure of dose gives just as satisfactory a fit to the data as using cumulative dose and its generalisations; however, taking account of the dust level is more appropriate biologically.

\section{ALTERNATIVE DOSE-RESPONSE MODEL}

The dose-response model used has a reasonable biological basis, but other models may be appropriate. An alternative is that the incidence rate of diagnosis of an adverse effect is proportional to the amount of dust in the lungs (see Appendix). The analyses have been repeated with this model, which was satisfactory for the case with a five-year lag provided that the half-life was at least five years.

\section{IMPLICATIONS FOR MODERN CONDITIONS}

The disease pattern observed in this study has occurred as a result of higher dust levels than those which occur now (Table 1). It is interesting to predict the likely disease pattern with current standards and the concentrations estimated to result in a given percentage of men with disease. This has been done for continuous lengths of exposure of 30,40 or 50 years. The percentage of men estimated to have reached the possible asbestosis category by the end of a period of exposure to $2 \mathrm{f} / \mathrm{cm}^{3}$ has been calculated and, in addition, the concentration necessary to limit this percentage to $1 \%$ has been estimated. These calculations have been based on the parameter estimates from the post-1950 group for both models for a range of values of the half-life time of dust elimination (Table 8).

Varying the half-life time of dust elimination has a marked effect. For example, after $\mathbf{4 0}$ years' exposure to $2 \mathrm{f} / \mathrm{cm}^{3}$, and using the logit dose-response 
Table 8 Estimated prevalence of possible asbestosis after uniform exposure to $2 \mathrm{f} / \mathrm{cm}^{3}$ and estimated concentration giving a prevalence of $1 \%$

\begin{tabular}{|c|c|c|c|c|c|c|}
\hline \multirow[t]{2}{*}{$\begin{array}{l}\text { Half-life of elimination of dust } \\
\text { from lungs }(y r)\end{array}$} & \multicolumn{3}{|c|}{$\begin{array}{l}\text { Estimated prevalence }(\%)-2 f / \mathrm{cm}^{3} \\
\text { Length of exposure }(y r)\end{array}$} & \multicolumn{3}{|c|}{$\begin{array}{l}\text { Estimated concentration }\left(f / \mathrm{cm}^{3}\right)-1 \% \text { prevalence } \\
\text { Length of exposure }(y r)\end{array}$} \\
\hline & 30 & 40 & 50 & 30 & 40 & 50 \\
\hline \multicolumn{7}{|l|}{ Logit model (no lag) } \\
\hline $0=$ cumulative dose & 2 & 4 & 7 & $1 \cdot 5$ & $1 \cdot 1$ & 0.9 \\
\hline 5 & 4 & 7 & 11 & $1 \cdot 0$ & 0.7 & 0.5 \\
\hline 10 & 5 & 9 & 15 & 0.8 & 0.5 & 0.4 \\
\hline 25 & 6 & 12 & 19 & 0.6 & 0.4 & 0.3 \\
\hline$x=$ no elimination & 7 & 14 & 24 & 0.5 & $0 \cdot 3$ & $0 \cdot 2$ \\
\hline \multicolumn{7}{|l|}{ Logit model (5-year lag) } \\
\hline $0=$ cumulative dose & 4 & 6 & 9 & $1 \cdot 0$ & 0.7 & 0.5 \\
\hline 5 & 6 & 10 & 14 & 0.4 & 0.3 & $0 \cdot 2$ \\
\hline 10 & 8 & 12 & 17 & 0.3 & $0 \cdot 2$ & $0 \cdot 1$ \\
\hline 25 & 8 & 14 & 21 & $0 \cdot 2$ & $0 \cdot 1$ & 0.1 \\
\hline$\infty=$ no elimination & 9 & 16 & 24 & $0 \cdot 2$ & $0 \cdot 1$ & $0 \cdot 1$ \\
\hline \multicolumn{7}{|l|}{ Alternative model (5-year lag) } \\
\hline 0 & - & - & - & - & - & \\
\hline 5 & 7 & 10 & 13 & $0 \cdot 3$ & $0 \cdot 2$ & $0 \cdot 1$ \\
\hline 10 & 8 & 12 & 17 & 0.3 & $0 \cdot 2$ & $0 \cdot 1$ \\
\hline 25 & 8 & 14 & 21 & 0.2 & $0 \cdot \overline{1}$ & $0 \cdot 1$ \\
\hline$\infty=$ no elimination & 9 & 17 & 26 & $0 \cdot 2$ & $0 \cdot 1$ & $0 \cdot 1$ \\
\hline
\end{tabular}

relationship with no lag period, the prevalence varies from $4 \%$ with cumulative dose to $14 \%$ with cumulative dose weighted by time since exposure (Table 8). Incorporating a five-year lag into the model changes this range to $6-16 \%$, and using the alternative model makes very little difference. Hence, the method of accumulating exposures to dust over a period of time to produce a single measure of exposure is critical, mainly because of the unknown rate of dust elimination.

It is impossible with the data in the present study to discriminate in a statistical sense between any of the possibilities listed in Table 8, except that those based on cumulative dose may be relatively unsatisfactory.

One reason for the wide range of values in Table 8 is that only six men had average exposures of less than $2 \mathrm{f} / \mathrm{cm}^{3}$, but all of the figures in the Table are below this value. Another reason is that the maxinum follow-up in the data is only 23 years, but longer exposures are considered. Therefore the figures in Table 8 are all predictions derived from extrapolations, and illustrate the difficulties of drawing any firm conclusions on the safety of present standards from data relating to the dusticr conditions which existed until recently.

\section{Discussion}

By restricting the main analysis to men first employed after 1950, two important sources of bias have been reduced. First, estimated dust concentrations for earlier years were not used, although it was necessary to use the thermal precipitator counts between 1951 and 1950. Second, the selective effect of men leaving the factory for health reasons was largely eliminated.

There are errors in both the response and dose in the data analysed. Evidence of uncertainty in response is provided by the differences in the recording of crepitations by the factory medical officer and the Pneumoconiosis Medical Panel. Even when the medical findings are not in dispute it does not follow that exposure to asbestos is necessarily the cause. Crepitations may be caused by bronchitis, and pulmonary fibrosis may be detected on the chest radiograph in the absence of exposure to asbestos; for example, Weiss (1969) reported its presence in $0.6 \%$ of non-smokers and $2.2 \%$ of smokers. The prevalence of crepitations and radiological changes in the absence of asbestos exposure in the area where the factory is situated could be established only by examining a control group; this was not done in the present study. The dust concentrations used were obtained from static sampling sites and. therefore, took no account of the work-style of individual men. This may be the reason why the dose-response relationship fitted the data just as well with time since first exposure as with the various measures of cumulative dose. The effect of errors in response and dose, even if it were valid to regard them as purely random, would be to give lower dust levels associated with low prevalences of signs than would have been the case if it had been possible to collect the data without error. Thus, for example, the dust concentrations given in Table 8 would have to be increased before being applied to a situation in which the dust was measured by personal samplers. 
Most of the men in the study had been employed elsewhere before starting work at the factory; only $40 \%$ started before age 30 . Of the 13 men in the post-1950 group who had possible asbestosis, five had worked in the cotton industry. One of these had been a stripper and grinder for 20 years and was considered to have reached the possible asbestosis category within eight years of first employment at the factory studied, the only sign within 10 years (Table 2). Another man who was certified as suffering from asbestosis after 12 years in the factory had previously been a chemical worker for 20 years; asbestosis was not confirmed at death. It seems likely, therefore, that some of the signs observed in this study were at least partly attributable to previous employment in other dusty occupations.

The association between smoking and signs of asbestosis (Table 6) is in agreement with Weiss (1971) who found pulmonary fibrosis in the chest radiograph in $40 \%$ of smokers and $24 \%$ of non-smokers among workers exposed to chrysotile asbestos.

The data have been analysed in terms of a family of exposure measures, an inherent feature of which is that there is the equivalent of an exponential decline in the amount of active material. This could arise as a result of both elimination of dust and a reduction in activity of the dust remaining. Beattie and Knox (1961) determined the mineral content after death in lungs of workers from the factory, and found no evidence of a decline in the first eight years after exposure had stopped. However, they took no account of changes in dust level; those who had survived for a period after leaving the factory were, on average, probably first exposed about 15 years earlier than those who died while still employed, and $70 \%$ of the men in the study had been employed before 1932. There is evidence that trace metals are leached from chrysotile asbestos in vivo (Morgan et al., 1971; Morgan et al., 1973). This leaching, and other changes within the lungs, may reduce the hazard of the remaining material. The range of measures was introduced because it was felt that the simplest measure, that of cumulative exposure, might not be completely satisfactory because of its inability to allow for the possibility of development of disease after exposure has ended. Crepitations appeared to develop in five men while they were not exposed, but in two of these the change could have been caused by observer differences. The changes in the other three men could have been attributable to the transient nature of the sign or to reasons other than asbestos exposure.

Because so few of the men have been retired for even five years, we are unable to discriminate between the different dose-response relationships. Data of this type from other sources would provide clues to the most appropriate value of the half-life time of dust elimination. If elimination were slow, then cases of asbestosis would be first diagnosed and certified in men who left the industry many years earlier; if this were not the case, then the use of cumulative dose would be reasonably valid. It is known that an excess incidence of lung cancer and mesothelioma occurs in men many years after the end of exposure (Newhouse, 1973) but info, mation is lacking on the diagnosis of asbestosis in former asbestos workers.

There are several reasons why the models might be inappropriate. First, if the diagnostic procedures were not uniform over the period 1961-73, then some of the recorded new cases could be attributable to a change in diagnostic criteria rather than to true clinical changes. The factory medical officer was replaced during this period and, in addition, lung function testing was introduced at about the same time. Second, the assumption that the amount of dust deposited in the lungs is a fixed proportion of the airborne concentration would not be valid if there had been changes in the particle size in the airborne dust cloud during the period 1951-72. In view of the changes in dust levels over this period, a change in the size distribution would not be surprising; however we have no relevant data.

A dose-response relationship between morbidity and asbestos exposure has been considered in two other studies. McDonald et al. (1974) studied several facets of disease, death, radiological changes, pulmonary function changes and respiratory symptoms and related these to the cumulative exposure measured as millions of particles per cubic foot times years (mpcf-yr). They concluded that there was a $1 \%$ risk of acquiring clinically significant disease for an exposure between 100 and 200 mpcf-yr. Some of their observations were based on a complete cohort but others only on current employees. Weill et al. (1975) considered lung function measurements and irregular small opacities on the chest radiographs and found little evidence of a dose-response relationship below 100 mpcf-yr. Using the results of simultaneous sampling with the impinger and fibre counting method they equated this dose with $200 \mathrm{f}-\mathrm{yr} / \mathrm{cm}^{3}$. Their observations were based on current employees only, and for some, exposure had started only shortly before the study.

The results of the present study are disappointing in that it is not possible to draw any definite conclusions on the effects of the present $2 \mathrm{f} / \mathrm{cm}^{3}$ standard. Comparison of the present results with those given earlier (British Occupational Hygiene Society, 1968; Berry, 1973) shows that there is a higher prevalence of crepitations at any dose than was observed previously. However, in view of the doubt that 
cumulative dose is an adequate measure of exposure, the prevalence of crepitations which would occur in those employed for a lifetime under the present standard can be predicted only within wide limits. Crepitations are not specific to asbestos exposure nor would their presence be considered as significant disease, defined as disability or shortening of life. Possible asbestosis is a better indicator but may not be either specific or significant disease; however it correlates well with certification (Figure 2). In the group first employed after 1950 the average cumulative exposure was $84 \mathrm{f}-\mathrm{yr} / \mathrm{cm}^{3}$, the average follow-up since first exposure was 16 years, and the prevalence of possible asbestosis was $6.6 \%$. In view of these findings there is no room for complacency about the $2 \mathrm{f} / \mathrm{cm}^{3}$ standard and efforts should be continued to reduce asbestos dust to as low a level as possible. At this stage it is impossible to state definitely that the standard is inadequate, because its introduction is so recent, and it is essential to follow up groups exposed to low levels in order to improve the data necessary for the formulation of better standards.

We are grateful to Drs P. G. Harries and V. H. Springett who read the chest radiographs (the other two readers were JCG and HCL); to Dr A. N. Dempsey of the Manchester Pneumoconiosis Medical Panel for allowing us access to data; to Dr P. C. Elmes who suggested making allowance for exponential elimination of dust from the lungs; to Dr J. C. Morris who provided extra information; to $\mathrm{Mr}$ J. Peto who suggested the alternative doseresponse model; to Dr J. C. Wagner who examined post-mortem material, and to all those who helped and encouraged us to carry out the study.

\section{References}

Beattie, J., and Knox. J. (1961). Studies of mineral content and particle size distribution in the lungs of asbestos textile workers. In Inhaled Particles and Vapours, pp. 419-433. Edited by C. N. Davies. Pergamon Press: Oxford.

Berry, G. (1973). Hygiene standards-theory and application. In Biological Effects of Asbestos, pp. 145-149. Edited by P. Bogovski, J. C. Gilson, V. Timbrell, and J. C. Wagner. International Agency for Research on Cancer, Scientific Publication No. 8. IARC: Lyon.

British Occupational Hygiene Society (1968). Hygiene standards for chrysotile asbestos dust. Annals of Occupational Hygiene, 11, 47-69.

British Occupational Hygiene Society (1973). Review of the hygiene standard for chrysotile asbestos dust. Annals of Occupational Hygiene, 16, 7.

British Thoracic and Tuberculosis Association (1975). Opportunist mycobacterial pulmonary infection and occupational dust exposure: an investigation in England and Wales. Tubercle, 56, 295-310.

Dreessen, W. C., Dallavalle, J. M., Edwards, T. I., Miller, J. W., Sayers, R. R., Easom, H. F., and Trice, M. F. (1938). A study of asbestosis in the asbestos textile in- dustry. Public Health Bulletin (Washington), No. 241. US Government Printing Office: Washington.

Holmes, S. (1973). Environmental data in industry. In Biological Effects of Asbestos, pp. 135-137. Edited by P. Bogovski, J. C. Gilson, V. Timbrell, and J. C. Wagner. International Agency for Research on Cancer, Scientific Publication No. 8. IARC: Lyon.

International Labour Office (1972). ILO U/C International Classification of Radiographs of the Pneumoconioses, 1971. Occupational Safety and Health Series No. 22 (revised). ILO: Geneva.

Jahr, J. (1974). Dose-response basis for setting a quartz threshold limit value. A new simple formula for calculating the 'lifetime dose' of quartz. Archives of Environmental Health, 29, 338-340.

McDonald, J. C., Becklake, M. R., Gibbs, G. W., McDonald, A. D., and Rossiter, C. E. (1974). The health of chrysotile asbestos mine and mill workers in Quebec. Archives of Environmental Health, 28, 61-68.

McVittie, J. C. (1965). Asbestosis in Great Britain. Annals of the New York Academy of Sciences, 132, 128-138.

Morgan, A., Holmes, A., and Gold, C. (1971). Studies of the solubility of constituents of chrysotile asbestos in vivo using radioactive tracer techniques. Environmental Research, 4, 558-570.

Morgan, A., Lally, A. E., and Holmes, A. (1973). Some observations on the distribution of trace metals in chrysotile asbestos. Annals of Occupational Hygiene, 16, 231-240.

Newhouse, M. L. (1973). Asbestos in the work place and the community. Annals of Occupational Hygiene, 16, 97-107.

Weill, H., Ziskind, M. M., Waggenspack, C., and Rossiter, C. E. (1975). Lung function consequences of dust exposure in asbestos cement manufacturing plants. Archives of Environmental Health, 30, 88-97.

Weiss, W. (1969). Cigarette smoking and diffuse pulmonary fibrosis. American Review of Respiratory Diseases, 99, 67-72.

Weiss, W. (1971). Cigarette smoking, asbestos and pulmonary fibrosis. American Review of Respiratory Diseases, 104, 223-227.

\section{Appendix}

\section{MEASURES OF EXPOSURE}

In this appendix, certain forms of dose-response relationships are discussed. First, it is necessary to define the dose, that is, to derive a measure of exposure in the situation in which exposure takes place over a period of years with different concentrations.

The simplest and most commonly used measure of exposure is the cumulative dose, which gives equal weight to the concentrations of airborne dust experienced in each year of exposure. Thus, for example, suppose a man started work in the factory at time zero and was exposed to a concentration of $c_{1}$ up to time $t_{1}$; this was followed by concentration $c_{2}$ from time $t_{1}$ to $t_{2} ; c_{3}$ from $t_{2}$ to $t_{3}$; and finally $c_{4}$ up to time $t_{4}$, the time the exposure is to be 
evaluated. In this example some of the concentrations could be zero to cope with a break in exposure, $c_{2}$ or $c_{3}=0$, or with retirement, $c_{4}=0$. Then the cumulative dose is given by:

cumulative dose $=c_{1} t_{1}+c_{2}\left(t_{2}-t_{1}\right)+\begin{array}{r}c_{3}\left(t_{3}-t_{2}\right)+ \\ c_{4}\left(t_{4}-t_{3}\right)\end{array}$

This is how the cumulative dose would be evaluated in practice, but to simplify a more general approach it may also be written as an integral. Suppose exposure started at time zero and is to be evaluated up to time $t$, and that the concentration at time $u$ is $c(u)$ for $0 \leqslant u \leqslant t$; again $c(u)$ would be zero during breaks in exposure or after retirement. Then

cumulative dose $=\int_{0}^{t} c(u) \mathrm{d} u$

This measure attaches no more importance to exposure a long time ago than to recent exposure, and does not alter after exposure has ended. Both of these properties are unrealistic for a disease, such as asbestosis, which is dependent more on early exposure than on recent exposure and which may develop after exposure has ended. The simplest way of allowing for both of these points was given by Jahr (1974) who suggested that each component of exposure should be weighted by the time which has elapsed since the exposure occurred. Thus, cumulative dose weighted by time since exposure is given by

$$
\int_{0}^{t}(t-u) c(u) \mathrm{d} u
$$

and, in practice, evaluated by summing contributions of the form

$$
c_{2}\left(t_{2}-t_{1}\right)\left\{t-\frac{1}{2}\left(t_{1}+t_{2}\right)\right\}
$$

over each period of exposure to a fixed concentration.

The weighting factor could be regarded as the time that the dust has been in the lungs if elimination has not taken place. Looking at the measure in this way, and postulating that elimination does occur, leads to a generalisation.

Suppose that, over the long term, dust is eliminated from the lungs at a rate proportional to the amount in the lungs, and the constant of proportionality is $\lambda$; in other words, in the absence of further exposure the amount of dust in the lungs declines exponentially at rate $\lambda$ and will be reduced to one half of its level in time $T=\ln 2 / \lambda$, the half-life time. The actual amount of dust deposited in the lungs is unknown, but is assumed to be proportional to the concentration. Then the amount of dust in the lungs at time $v$ is, apart from a constant of proportionality, $A(v)$ given by:

$$
A(v)=\int_{0}^{v} c(u) \mathrm{e}^{-\lambda(v-u)} \mathrm{d} u
$$

If it is supposed that each component of dust which was deposited in the lungs contributes to the dose for the time it remains in the lungs then the dose $D(t)$ evaluated at time $t$ is given by:

$$
\begin{aligned}
& D(t)=\int_{0}^{t} A(v) \mathrm{d} v \\
= & \int_{0}^{t} \int_{0}^{v} c(u) \mathrm{e}^{-\lambda(v-u)} \mathrm{d} u \mathrm{~d} v \\
= & \int_{0}^{t} c(u) \int_{u}^{t} \mathrm{e}^{-\lambda(v-u)} \mathrm{d} v \mathrm{~d} u \\
= & \frac{1}{\lambda} \int_{0}^{t} c(u)\left\{1-\mathrm{e}^{-\lambda(t-u)}\right\} \mathrm{d} u
\end{aligned}
$$

This is the generalised measure which, except for infinite $\lambda$, has the properties that, first, it gives more weight to exposure a long time ago than to recent exposure and, second, it continues to increase after exposure has ended. If $\lambda$ tends to infinity then $D$ tends to zero, but in such a way that $\lambda D$ tends to cumulative dose. Thus, in effect the cumulative dose may be considered as a special case of the generalised dose when elimination of dust from the lungs takes place very quickly. If $\lambda$ tends to zero, then $D$ tends to the cumulative dose weighted by time since exposure which, therefore, is also a special case of the generalised measure when there is no elimination of dust from the lungs.

To summarise, the generalised measure consists of a family of dose measures with each member of the family defined by the parameter $\lambda$, or, in an equivalent manner, by the half-life time $T$. The full family is obtained by allowing $T$ to vary from zero to infinity. The approach followed here is akin to that of the British Thoracic and Tuberculosis Association (1975).

\section{DOSE-RESPONSE RELATIONSHIPS}

If $P$ is the prevalence of a sign at dose $D$, then a dose-response relationship is defined by a functional relationship between $P$ and $D$, that is, $P=\mathrm{f}(D)$. All the relationships considered are such that $P$ is zero when $D$ is zero, and as $D$ increases above zero then so also does $P$; this excludes relationship 
with a threshold, i.e. $P$ zero for all values of $D$ below some non-zero threshold.

The first dose-response relationship is defined by:

$$
\ln \{P /(1-P)\}=a+b \ln (D)
$$

This is similar to that used previously (British Occupational Hygiene Society, 1968), which was based on the assumption that the distribution of dose at which a sign first occurred is log-normal. The relationship now being used differs only in that a logit transformation has been applied to $P$ instead of a probit transformation. As the logit and probit transformations are approximately equivalent, this modification makes negligible differences to the fitted relationships, and has been used to simplify the calculations.

An alternative way of looking at the response is to consider the incidence rate of new cases, $I$, instead of the prevalence, $P$. The incidence and prevalence are related by:

$$
I=\frac{\mathrm{d} P}{\mathrm{~d} t} /(1-P)
$$

It can be shown easily that the logit dose-response relationship may be written as

$$
I=b P A / D
$$

where $A$ is the amount of dust in the lungs as defined earlier.

If, instead of assuming that the distribution of dose at occurrence of a sign is approximately lognormal, it is assumed that the incidence of cases is proportional to the amount of dust in the lungs, then an alternative dose-response relationship is obtained:

$$
I=c A
$$

which may also be written in the form:

$$
\ln (1-P)=-c D
$$

Both the above relationships have equated the prevalence or incidence of a sign at time $t$ with the dose evaluated up to time $t$. This is equivalent to assuming that the effect of dust deposited in the lungs may be immediate. This may be unrealistic and, instead, it could be assumed that there is a lag period of length $w$ for the development of an observed effect after the dose responsible has been attained. The dose-response relationship then has the form $P(t)=f\{D(t-w)\}$.
FITTING THE DOSE-RESPONSE

RELATIONSHIPS

For a sign, such as crepitations, a man is known either to have reached time $t_{1}$ without crepitations or to have developed crepitations at some time between $t_{1}$ and $t_{2}$, where $t_{1}$ is the time of the latest medical examination at which crepitations were not recorded and $t_{2}$ is the first medical examination at which they were recorded. The log-likelihood of the observations, $L$, may be written:

$$
L=\Sigma \ln \left\{1-P\left(t_{1}\right)\right\}+\Sigma \ln \left\{P\left(t_{2}\right)-P\left(t_{1}\right)\right\}
$$

where the first summation is over men without the sign, and the second summation is over men with the sign. Substituting for $\boldsymbol{P}$ using the dose-response relations, $L$ is dependent on the parameters $a, b, T, w$ or $c, T, w$. An attempt was made to estimate these parameters by the method of maximum likelihood, proceeding as follows.

For the logit model with no lag period i.e. $w=0$, and for a fixed value of $T$, the parameters $a$ and $b$, or $c$, were estimated iteratively by the Newton Raphson method. This was repeated over a grid of values of $T$, from zero to infinity, in order to find the maximum likelihood estimate of $T$. For crepitations the loglikelihood increased as $T$ increased from zero but, for $T$ greater than 10 years, $L$ was almost constant, showing a variation of only 0.25 in the range 10 to infinity. The $95 \%$ confidence interval for $T$ was obtained as the interval in which $L$ was within 1.92 of its maximum, half of the $95 \%$ critical value for a $\mathbf{S}^{2}$ test with one degree of freedom. This confidence interval was from three years to infinity, so that it was impossible to estimate $T$ with any precision.

The alternative model was fitted in a similar manner but gave a worse fit than the logit model. This was to be expected, as the alternative model contains one less parameter than the logit model, but if the alternative model is considered as satisfactory as the logit model only if the log-likelihood of the former is within 2.0 of the latter, then the alternative model was not satisfactory.

The whole process was repeated with a lag period of five years. It was still not possible to estimate $T$ with any precision, and its $95 \%$ confidence inter val was from two years to infinity. The alternative model gave as satisfactory a fit as the logit model, provided that $T$ was at least five years.

Finally, the same procedure was applied to the sign of possible asbestosis. A similar pattern of results was obtained except that, because there were fewer cases, the confidence intervals for $T$ were even wider than were those for crepitations.

It was not possible to attempt to estimate the lag 
period by maximum likelihood because of the sudden changes in the concentrations when a man changed jobs. This meant that $L$ was not differentiable with respect to $w$ and prevented the application of maximum likelihood theory. However a graphical comparison of the observed and fitted dose-response relationship suggested that there were insufficient data to discriminate between the model without a lag period and one with a lag period of five years. The lag period cannot be much more than five years as there was one case of possible asbestosis only $7 \cdot 25 \mathrm{yr}$ after first exposure. 